\title{
Mineralogical and Geochemical Characteristics of Graphite-Bearing Rocks at Chenjere Area, South-Eastern Tanzania: Implications for the Nature and Quality of Graphite Mineralization
}

\author{
Charles D Moye ${ }^{1,2^{*}}$ and Michael M Msabi ${ }^{1}$ \\ ${ }^{I}$ Department of Geology, College of Earth Sciences and Engineering, University of Dodoma, P. O. \\ Box 11090, Dodoma, Tanzania \\ ${ }^{2}$ Geological Survey of Tanzania, P. O. Box 903, Dodoma, Tanzania \\ *Corresponding author, e-mail: chalemoye@gmail.com \\ Received 6 Oct 2020, Revised 17 Mar 2021, Accepted 21 Apr 2021, Published May 2021 \\ DOI: https://dx.doi.org/10.4314/tjs.v47i2.11
}

\begin{abstract}
This study focused on the mineralogical and geochemical characteristics of graphite-bearing rocks at Chenjere area by conducting surface geological mapping, geochemical and petrographical analyses with the intention of characterizing the nature of graphite occurrence in these lithological units. This paper presents results of the flake size, grade and mineralization extension of graphite in the graphitic gneiss. Field observations, petrographic investigation and comparison with other studies indicate that graphite occurrence at the Chenjere area is of sedimentary origin which fall under syngenetic type. The petrographic study revealed that nature of metamorphism of rocks in the Chenjere area is of high grade (amphibolite facies). Both field observations and petrographic studies indicate that minerals in the rock associated with graphite include quartz, feldspar (mostly K-feldspar) and biotite. Further, the mineralized zones are concordant to the rest of the lithologies of the area and biotite gneiss is forming the hangingwall and footwall. The rocks' foliation is generally NE striking and dipping SE with the dip amount ranging from 30 to 60 degrees. The graphite mineralization at the study area occurs as medium to coarse grained crystalline, flake type graphite with long axis of up to 1000 micrometres in size. Graphite flakes are disseminated and oriented in the host rock that represents a normal metamorphic fabric. Geochemical results indicate that graphite contents in the host graphitic gneiss range from 3.03 wt.\% to 16.00 wt.\%. Mineralogy and texture of the graphite at Chenjere area meet the standards required for industrial applications in various advanced technologies.
\end{abstract}

Keywords: Graphite Mineralization, Flake Graphite, Chenjere Area.

\section{Introduction}

Graphite is among the common naturally occurring solid allotropes of carbon with weak van der Waals forces in its hexagonal sheets. It has perfect cleavage with highest softness and greasy feeling (Meunier 2015, Palosaari et al. 2020). It is the most stable form of carbon at room temperature and atmospheric pressure (Puronaho 2018). It has both non-metallic and metallic properties with a high melting point of $3550{ }^{\circ} \mathrm{C}$ (Mitchell 1993, Simandl et al. 2015). Graphite can be classified as either naturally occurring or produced synthetically (Robinson et al. 2017). Natural graphite is formed either syngenetically or epigenetically (Bullock and Morgan 2015). Syngenetic graphite is formed by metamorphism of the preserved organic materials in the sediments (Rosing-Schow et al. 
2017), while epigenetic is formed by the precipitation of carbon from $\mathrm{C}-\mathrm{H}-\mathrm{O}$ fluids in the veins during retrograde metamorphism (Bullock and Morgan 2015, Simandl et al. 2015). Syngenetic results in two categories of graphite, namely crystalline flake graphite and microcrystalline or amorphous graphite (Mitchell 1993, Wissler 2006, Simandl et al. 2015). Vein type or lump graphite results from epigenetic processes (Puronaho 2018). For syngenetic graphite, the crystallinity increases with metamorphic temperatures, hence the quality in terms of flake size and crystallinity depends on the grade of metamorphism (Gautneb and Tveten 2000, Bullock and Morgan 2015).

Graphite has numerous unique physical and chemical properties such as high refractory, elasticity, high electrical conductivity, compressibility, chemical inertness, non-poison and lubricity (Wissler 2006). These properties make it non-replaceable and rare industrial mineral for currently high technological applications (Rosing-Schow et al. 2017). According to Simandl et al. (2015), the world natural graphite production was estimated to be 1.17 million tonnes in 2014 with most of it originating from China (67\%), India (15\%) and Brazil (7\%). Though China is the main producer in the world, the easily oxidized graphite to mine in the near-surface has been mined out (Rosing-Schow et al. 2017); as a result has restricted graphite exportation, and thus, there is graphite supply pressure globally (Sunkari and Zango 2018).

The viable economic world-class deposits of graphite are from the two geological settings, which are either Archean or
Neoproterozoic metamorphic belts (Sunkari and Zango 2018). There are reported occurrences of graphite in the vast Neoproterozoic Mozambique Mobile Belt (NMMB) of Tanzania stretching from North to South in the eastern side of the country (Figure 1; Fozzard 1956, Leger et al. 2015). Though there are many occurrences of graphite in the country, so far, there is no significant production of this mineral (Figure 1; Leger et al. 2015). As an industrial mineral, graphite needs a lot of specifications to be met (Sandmann et al. 2014). Hence, studies on its mineralogical and geochemical characteristics are vital in establishing its industrial specifications and resource development. The early studies on graphite occurrences in NMMB and the Chenjere area were mainly focused on reporting the regional occurrence of the graphite. These studies inadequately defined mineralogical and geochemical characteristics of this mineral occurrence (Fozzard 1956, Leger et al. 2015).

Therefore, given its current economic potential and worldwide supply concerns, this study investigated the mineralogical and geochemical characteristics of Chenjere graphite deposit through geochemical analysis and petrographic studies.

\section{Regional Geology}

The Chenjere area is underlain by metamorphic basements with sedimentary and igneous parentage of the East African Orogen (EAO), also known as the NMMB or PanAfrican Mozambique belt of East Africa (Figure 1; Kröner et al. 2003, Thomas et al. 2014, Leger et al. 2015). 
Tanz. J. Sci. Vol. 47(2), 2021

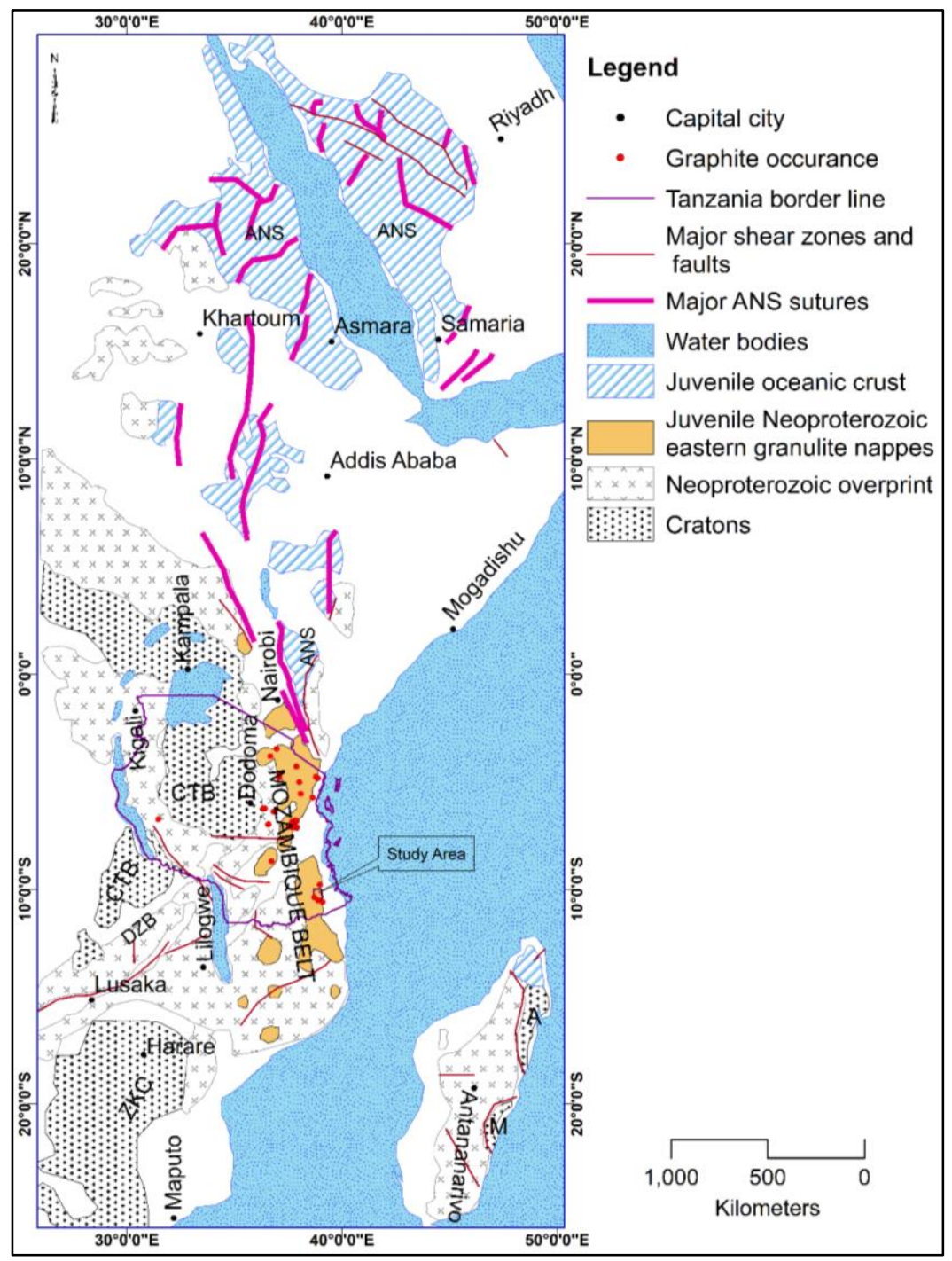

Figure 1: Distribution of crustal domains in the EAO (East African Orogen) and graphite occurrences in Tanzania (modified after Fritz et al. 2013, Thomas et al. 2014, Leger et al. 2015). CTB = Congo-Tanzania-Bangweulu Cratons; ZKC = Zimbabwe-Kalahari Cratons; A = Antogil Craton; $\mathrm{M}=$ Masora Craton; ANS = Arabian Nubian Shield and DZB = Damara-Zambezi Belt.

According to Feneyrol et al. (2013), the rocks of the EAO can be divided into four distinct lithological units: (i) juvenile oceanic crust (ophiolites) exclusively found in the northern parts (Figure 1); (ii) island arc magmatic rocks also found in the northern parts of the orogeny (Figure 1); (iii) metamorphic rocks with metasediments such as quartzite, pelitic gneiss, graphitic gneiss and marble, granulite complexes and reworked continental crustal materials hosting gemstones and graphite deposits found mostly in the Tanzania, Mozambique and Madagascar (Figure 1); and (iv) late extensive intrusions, mainly granitoids and anorthositic gabbros mainly in the Kuungan belt (Figure 1; Thomas et al. 2014). 
In Tanzania, MMB is divided into Western Granulites and Eastern Granulites mostly based on their protoliths ages (Thomas et al. 2014, Leger et al. 2015). The western granulites are comprised of older protolith of Meso to Neoarchean, while the eastern granulites are comprised of Meso to Neoproterozoic protoliths. Eastern granulites have inclusion of juvenile lithologies, while the western granulites have none. Both western and eastern granulites had the major Neoproterozoic tectono-thermal overprint ageing around 640 Ma (Kröner et al. 2003, Leger et al. 2015).

The MMB, also known as the "Pan-African Gems or Graphite Belt", is essentially consisting of medium to high-grade gneisses and large granitoid bodies. It extends southwards from the Arabian-Nubian Shield into southern Ethiopia, Kenya and Somalia through Tanzania to Malawi and Mozambique, and also includes Madagascar and Antarctica continent (Figure 1; Dissanayake and Chandrajith 1999, Kröner and Stern 2005). These events came up with high-grade granulites, gneisses and migmatitic lithologies due to deformation and metamorphism (Kröner and Stern 2005). This belt is characterized by a continent-continent collision in its northern and southern parts (Jacobs et al. 2008).

Chenjere area occurs within eastern granulites domain with Neoproterozoic "Eastern Granulites" nappes excluded (Thomas et al. 2014). The eastern domain is dominantly comprised of granulites, graphite bearing gneisses, marbles, quartzites and schist as well as post-orogenic granites and gemstone bearing pegmatites (Thomas et al. 2014, Leger et al. 2015).

\section{Local Geology of the Study Area}

The study area is mostly covered by thick reddish-brown soil as reported by Fozzard (1956) in the geological map of QDS 293 with a scale of 1:125000. It is predominantly composed of crystalline basement of metasedimentary rocks, metamorphosed pyroxenite and peridotite, amphibolites and pegmatite and quartz veins that form part of
EAO (East African Orogen) (Fozzard 1956, Thomas et al. 2014). There are patches or tiny mosaics of some sedimentary rock units of chocolate-coloured silicified sandstones or conglomerates of Cretaceous age. These are forming thin layers and dispersed patches over the dominant crystalline sedimentary rock units. Their thickness increases towards eastern parts to the Rondo forest (Fozzard 1956). The metasedimentary units include quartzofeldspathic gneiss \pm garnet and biotite, graphitic quartzite gneiss \pm fuchsite and sillimanite, graphitic quartz feldspathic schist \pm fuchsite, biotite schist \pm garnet, amphibolite gneiss with \pm garnet, meta-ultramafic rock units such as pyroxenite and peridotites, quartzites and marble (Fozzard 1956). The foliations are mainly striking $\mathrm{NE}$ to $\mathrm{SW}$ (Fozzard 1956, Thomas et al. 2014). The dip amount is shallow, moderate and steep with either dipping to SE or NW (Fozzard 1956). Mineral lineations are mostly parallel to the foliations forming dip-slip lineation. However, strike and oblique strike-slip lineations had been reported (Thomas et al. 2014).

\section{Methodology \\ Geological mapping, sample collection and preparations}

The geological mapping was done following the traverses that were cross-cutting the strike of the main foliation of NE-SW as reported by Fozzard (1956). Hence, the traverses were planned to be SE-NW. During geological mapping, the main emphasis was on the graphitic lithologies. A total of forty-five (45) samples were collected during this mapping program and sent to the Geological Survey of Tanzania (GST) Laboratory for preparation and analysis.

Nine (9) out of forty-five (45) samples were selected for petrographic studies. Sample preparation involved cutting large sample to smaller pieces to fit glass slides using a big diamond blade. Rock thin sections were mounted on glass slides used of $3 \mathrm{~mm}$ by 25 $\mathrm{mm}$ by $45 \mathrm{~mm}$ dimensions by using Canada balsam. Then samples were further cut to 
approximately $1 \mathrm{~mm}$ thickness. The mounted samples were ground using abrasive materials starting with rough abrasives to smooth ones to a size of about $30 \mu \mathrm{m}$, which is the required thickness suitable for examination under optical microscope. In addition, these thin sections were polished for better results (Barker 2014).

\section{Petrographic investigation}

The petrographic study was done in GST laboratory for nine (9) samples which were graphitic gneisses, biotite gneisses and quartzofeldspathic gneiss. The optical microscope Zeiss Optika was used to examine the prepared thin sections. The reflected light (RL) was used to study graphite as it is an opaque mineral and the transmitted light (TR) for other minerals using both plane-polarized light (PPL) and cross-polarized light (XPL). Different minerals were identified with their textural characteristics and microstructures. The mineral abbreviations used in the photomicrography followed the standard abbreviations proposed by Whitney and Evans (2010).

\section{Sample preparation and loss on ignition}

A total of forty-five (45) samples were delivered to GST laboratory for loss on ignition (LOI) analysis. Out of these, 10 were quality assurance (QA)/quality control (QC) samples. These samples were analyzed for total graphitic carbon grade (TGC) content and results are presented in percentages. The samples were pulverized to $75 \mu \mathrm{m}$ through a jaw crusher and then swimming mill machines. The pulverized samples were weighed by electrical analytical balance with an accuracy of $0.0001 \mathrm{~g}$ to get 1 g. The analysis of graphite by LOI was mainly entailing sequential heating and weighing of the samples in the oven and muffle furnace. The ignition temperature for graphite in the GST laboratory manual was $900{ }^{\circ} \mathrm{C}$. The sample was heated in the oven at $104{ }^{\circ} \mathrm{C}$ for one hour to remove water content in the sample. After weighing the sample from the oven, the muffle furnace was used to remove volatile matters such as sulphides and chlorites that may be contained in the sample at $800{ }^{\circ} \mathrm{C}$ for seven minutes. Finally, after weighing the cooled sample heated at 800 ${ }^{\circ} \mathrm{C}$, the sample was heated at $900{ }^{\circ} \mathrm{C}$ for ignition for four hours. The equation suggested by Heiri et al. (2001) (Equation 1) was used to determine the grade of graphite in terms of percentages.

$\mathrm{TGC}=\frac{W 800-W 900 \times 100}{W 800} \ldots \ldots . .($ Equation 1$)$.

Where: W800 was weight at $800{ }^{\circ} \mathrm{C}$, and W900 was weight at $900{ }^{\circ} \mathrm{C}$.

\section{Results}

The main findings of this study are the grade and flake size of graphite. Other findings include type and nature of graphite mineralization and its structural trend specifically in the study area. Extension and the relationship of graphite occurrence with the host and surrounding lithologies are also presented. The study area is mainly dominated by metasedimentary rocks of MMB. Most of these rocks are felsic with a general NE-SW trend with few exceptions (Figure 2). In some few places, these rocks are intruded concordantly by ultramafic units mainly pyroxenites and sporadically peridotite. The graphite-bearing lithologies occur in four prominent areas, namely Mtimbo, Matochi, Ng'imbwa and Nakapelo (Figure 2).

\section{Field observations and lithological relationships}

Red soil is the main regolith observed and dominated the southeast side of the study area, whereas, alluvium occurred mostly in the northeastern parts of the study area (Figure 2). Quartzo-feldspathic gneisses are forming the topographic edifices of the area, and these are mainly located in the central part (Figure 2). These rocks are foliated with oblique dip-slip mineral lineation (Figure 3a). 


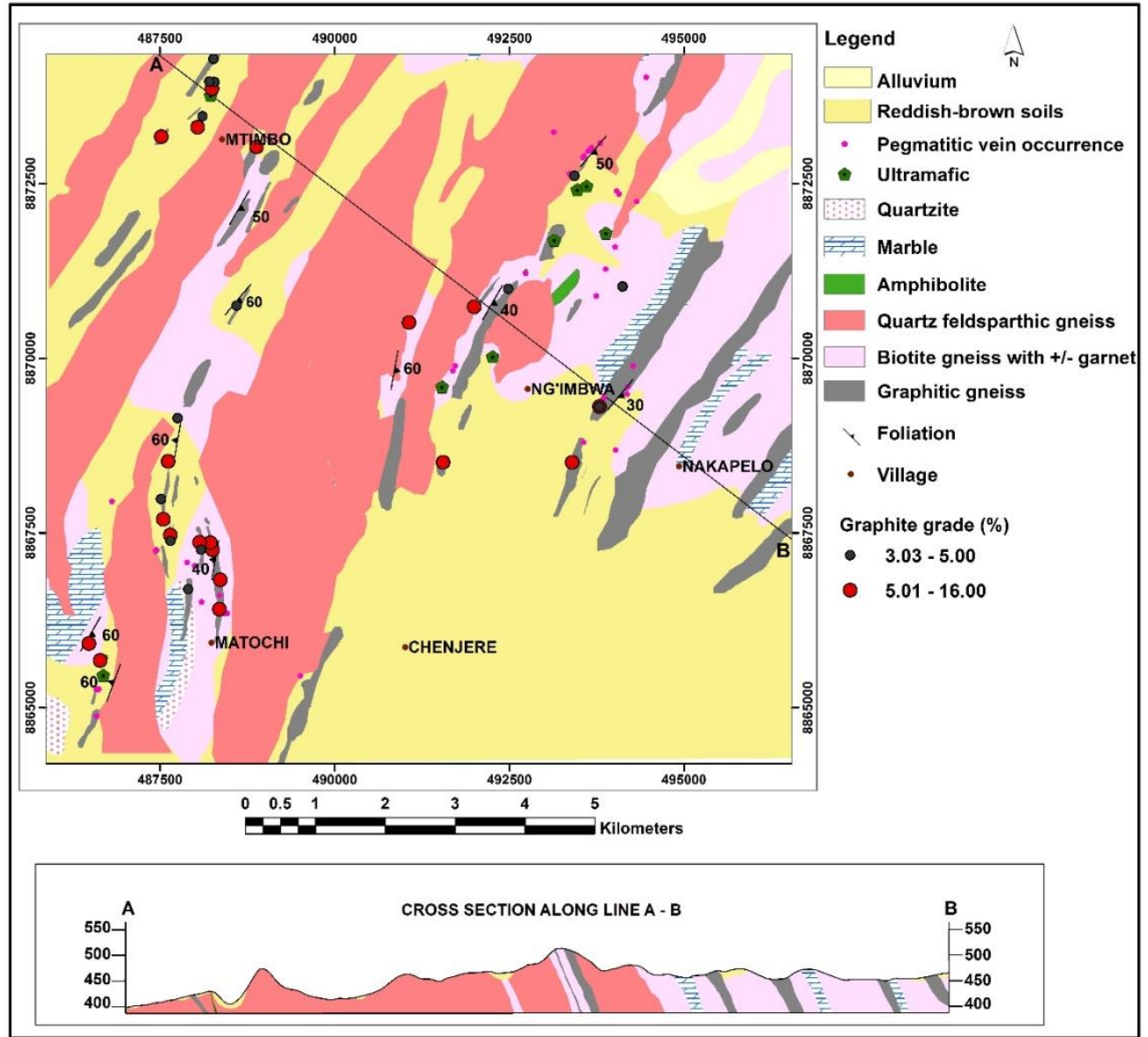

Figure 2: The geological map of the study area showing the distribution and the relationship between graphitic gneiss and other lithological units encountered during mapping. A-B is the cross-section line through most of the lithologies and the polar plot showing the foliation trends predominantly NE-SW.

The major rock-forming minerals in these rocks are feldspars, quartz, muscovite and biotite, with the latter two occurring in minor amounts. These rock units are sometimes associated with the garnet and sillimanite. However, they are chiefly deprived of graphite flakes.

Biotite gneiss is the second most dominant unit in the area forming the footwall and the hangingwall of the graphitic gneiss (Figure 2). This rock is black to grey coloured, strongly foliated with medium to coarse-grained $\mathrm{K}$ feldspar, plagioclase, muscovite and biotite \pm garnet (Figure 3b). The rock occurs in hill flanks and rarely on tops. Amphibolites, encountered in the central part of the area with limited exposure (Figure 2), are black to grey with hornblende and plagioclase feldspars as the major rock-forming minerals, whereas green diopside occurs as a minor constituent (Figure 3e). Diopside sometimes shows the pity weathering on the rock surface.

Intrusive rocks in the area are commonly ultramafic rocks and pegmatites. The ultramafic rocks are divided into two units, namely pyroxenites and peridotites. These 
ultramafic intrusives are not mappable but generally have varying thickness of up to a metre scale (Figure 2). They occur as thin bands concordant to the main foliation of NE to SW with pyroxenite being the most dominant. Pyroxenite is composed of very coarse-grained (up to $1 \mathrm{~cm}$-sized grain) pyroxenes, with distinctive knobbly-weathered surfaces (Figure 3f). Pegmatites are also too thin to be mapped. They are comprised of very coarse grains of up to $20 \mathrm{~mm}$ of $\mathrm{K}$-felspar and quartz with minor biotite and rare black tourmaline in some units. They cross-cut different lithologies commonly biotite and graphitic gneisses, respectively (Figure 3b).

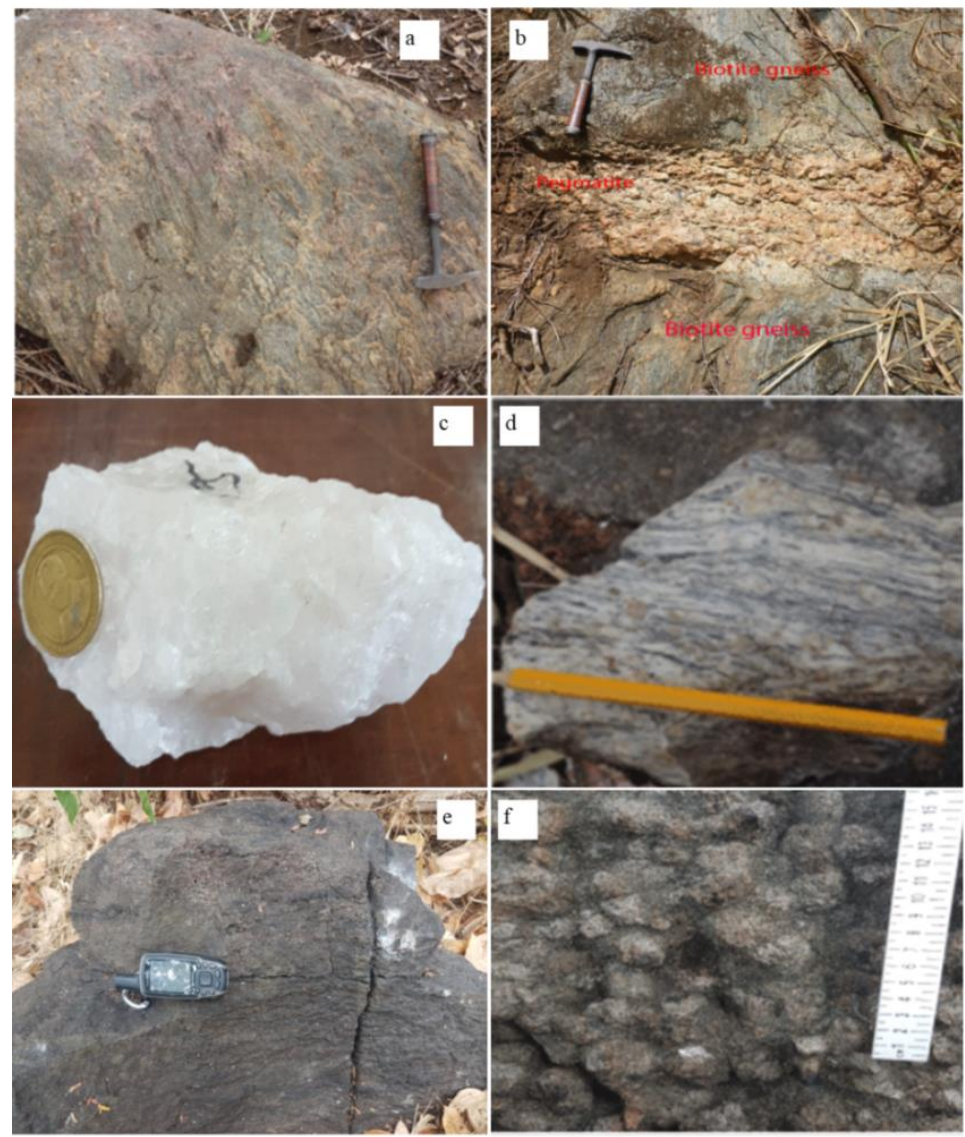

Figure 3: Field photographs showing a) Quartzo-feldspathic gneiss outcrop, b) Biotite gneiss cross-cut by pegmatite vein, c) White quartzite, d) Graphite bearing marble, e) Amphibolite and f) Pyroxenite with knobbly weathering.

The typical metasedimentary rocks in the study area are quartzite and marble. Quartzite occurs in the vicinity of graphitic gneiss. This unit occurs mostly in the SW parts of the study area juxtaposed to marble and graphitic lithologies (Figure 2 and Figure 3c). Marble units form a boundary with graphitic units or just in the vicinity of these lithologies (Figure 2). Few graphite flakes form lineation at the outcrop scale within marble units but not exceeding 1 vol.\% TGC grade based on the field observations (Figure 3d). Graphitic gneisses are clustered in four localities and striking concordantly with the rest of the 
lithologies that are striking NE-SW (except few) (Figure 2). The extensions of graphitic gneisses along the strike length are in order of hundred metres to few kilometres (Figure 2), although there are variations of thickness along the same strike length. Most of the surface graphitic gneisses are weathered and/or altered to oxides and hydroxides of iron, commonly hematite and limonite (Figure 4). Weathering and alteration make these rocks soft and easy to break by hands; however, the graphite flakes remained un-weathered (Figure 4b).
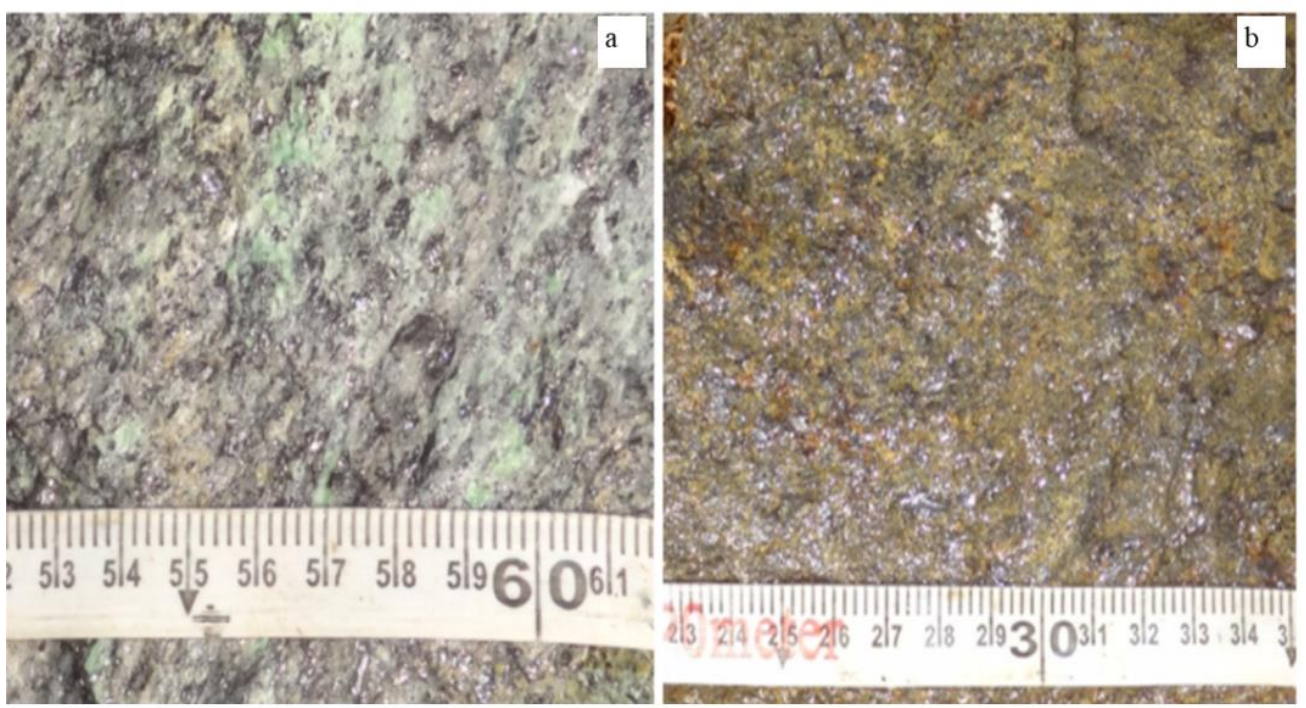

Figure 4: Graphite hand specimen showing (a) fresh graphitic gneiss and (b) oxidized graphitic gneiss.

\section{Petrographic results \\ Graphitic gneiss}

The colour of graphite flakes under both PPL and XPL is black, while in the RL is yellow to pale yellow (Figure 5 through Figure 8). The graphite flakes have lath shape with long and short axis (Figure 6). The flake sizes of the graphite observed under the optical microscope ranged from medium to coarse. They have the average long axis of $300 \mu \mathrm{m}$ with the maximum length of $1000 \mu \mathrm{m}$, whereas, the short axes have the average width of $50 \mu \mathrm{m}$ (Figure 5 to Figure 8). The silicate gangue minerals include mainly quartz, K-feldspar, plagioclase and biotite. The graphite flakes occur along the grain boundary of these silicate minerals. They are disseminated in the mineral matrix of the host rock. Moreover, they are oriented to sub-oriented in the mineral matrix of the host rock. Quartz crystals are the main constituents in the graphitic gneiss. The low-grade graphitic gneisses are comprised of garnet in the mineral matrix (Figure $7 d$, e, $f$ and Figure 8). 


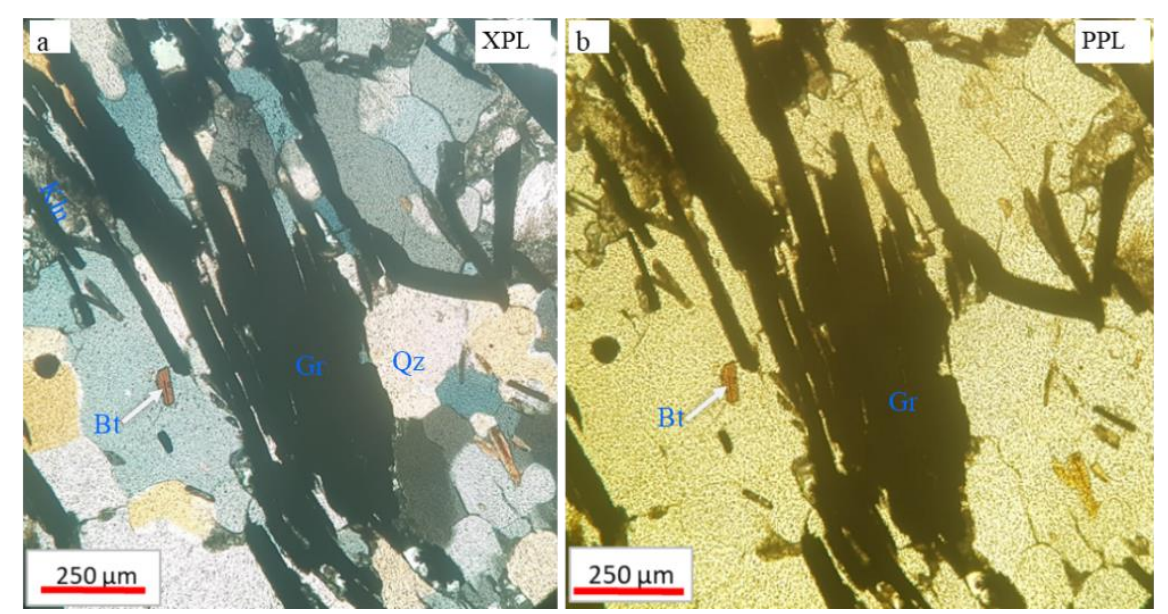

Figure 5: Photomicrographs of graphitic gneiss ( $a$ and $b$ ) showing the distribution of graphite flakes in the host rock and the flake orientation. Abbreviations: $\mathrm{Qz}=$ quartz, Kln $=$ Kaoline, $\mathrm{Bt}=$ Biotite and $\mathrm{Gr}=$ Graphite.

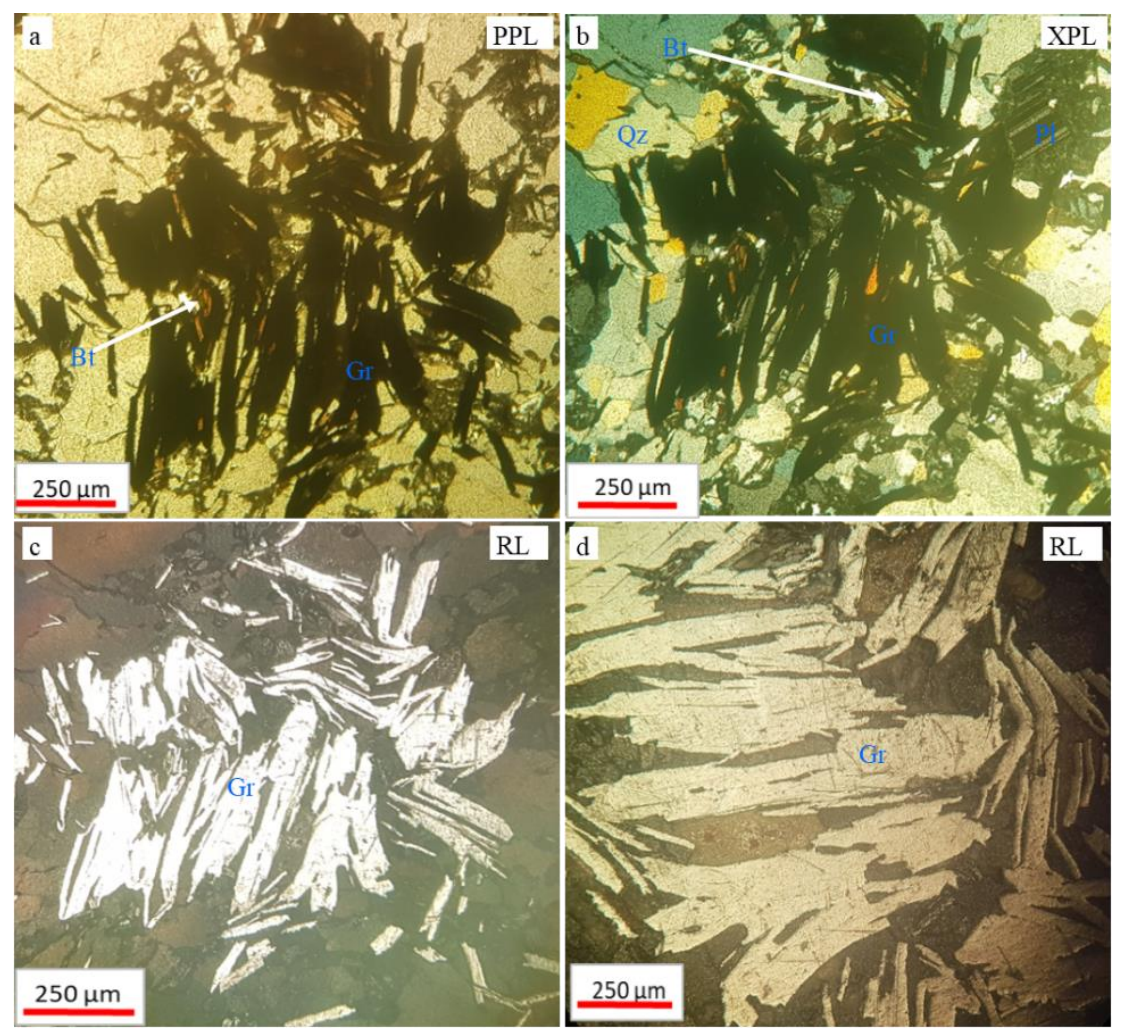

Figure 6: Photomicrographs of graphitic gneiss showing the distribution of graphite flakes and their relationships with the silicate minerals. (a) Thin section under PPL; (b) XPL and (c and d) RL. Abbreviations Qz $=$ Quartz, Bt = Biotite, Pl = Plagioclase and $\mathrm{Gr}=$ Graphite. 
Moye and Msabi - Mineralogical and geochemical characteristics of graphite-bearing rocks ...

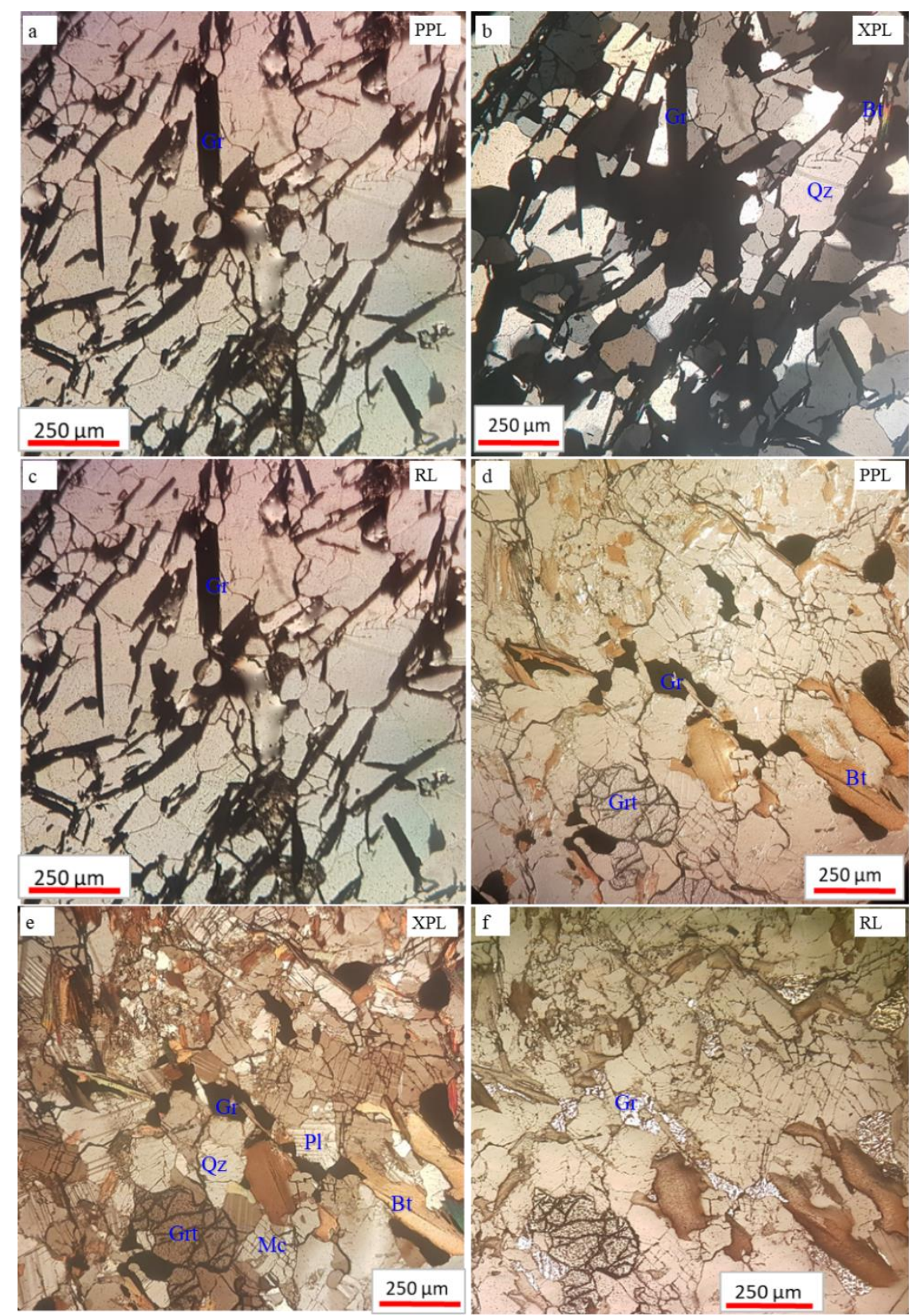

Figure 7: Photomicrograph of graphitic gneiss for medium grade (a, b, c) and low grade (d, e, f). Abbreviation: Grt $=$ Garnet and Mc $=$ Microcline. 

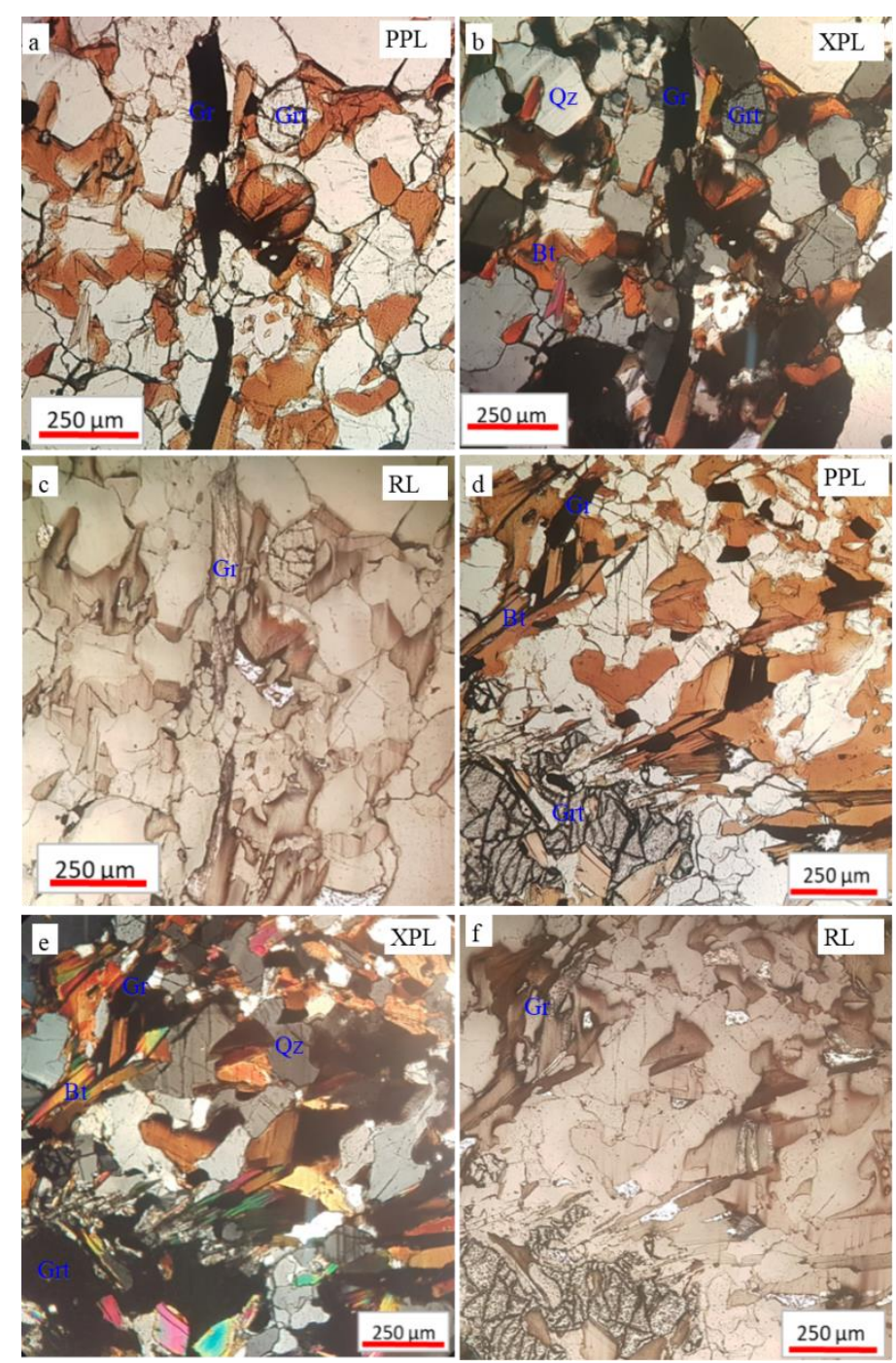

Figure 8: Photomicrograph of two low grade graphitic gneisses.

Biotite and quartzo-feldsparthic gneiss

Biotite and quartzo-feldspathic gneisses comprised of traces or no graphite flakes in the study area (Figure 9). Most of the biotite gneisses are chiefly composed of plagioclase, microcline and biotite (Figure 9a, b, c, and d) Plagioclase and microcline are commonly courser crystals (Figure 9a and b). Biotite grains are medium to fine with preferred orientation. On the other hand, mineral grains of quartzo-feldspathic gneiss are poorly oriented with the size ranging from medium to coarse. This lithology is composed of mainly quartz and feldspars, with biotite as the minor constituent (Figure 9e and f). Other secondary minerals include kaolin and epidote. For the feldspars, the plagioclase is more abundant than K-feldspar (Figure 9e and f). Plagioclase grains are displaying the insipient alteration to kaolin (Figure 9e and f). Quartz crystals show the conchoidal fractures filled with the kaolin. 


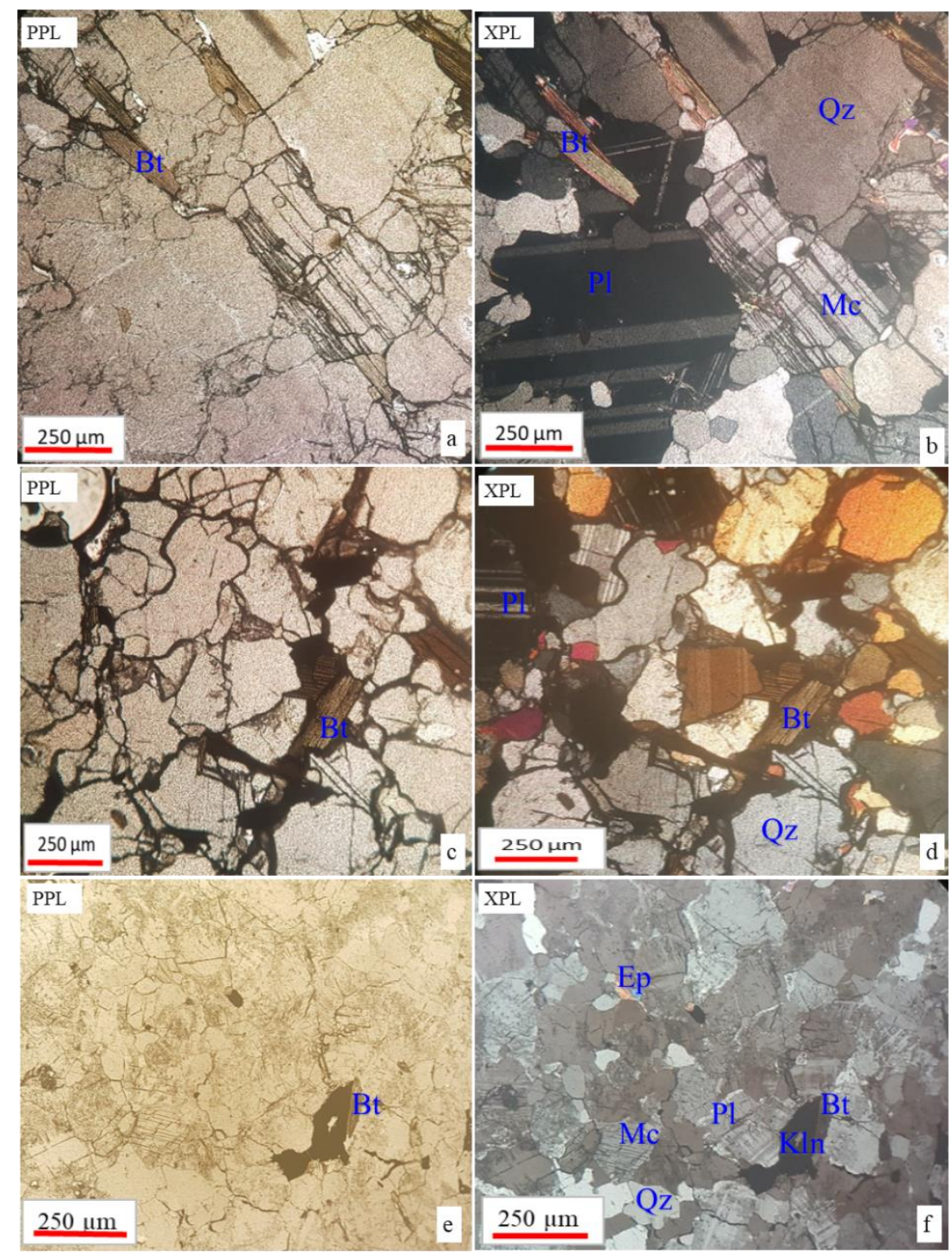

Figure 9: Photomicrographs of biotite gneiss (a to d) and quartzo-feldspathic gneiss (e and f). Abbreviation: $\mathrm{Ep}=$ epidote.

\section{Geochemical results}

The geochemical results are for the graphite analysis by LOI. The graphite grade is presented in the percentages and plotted in the graph (Figure 10).

\section{Graphite analysis results}

The samples collected and delivered to the GST laboratory were graphitic rock samples with varying field graphite grades. They were analysed by LOI methods and the grade of total graphitic carbon contents are given in terms of percentages. Figures 2 shows the spatial distribution of the analysed graphite grades. The highest and lowest grades were 16 wt.\% and 3.03 wt.\%, respectively (Figure 10). 


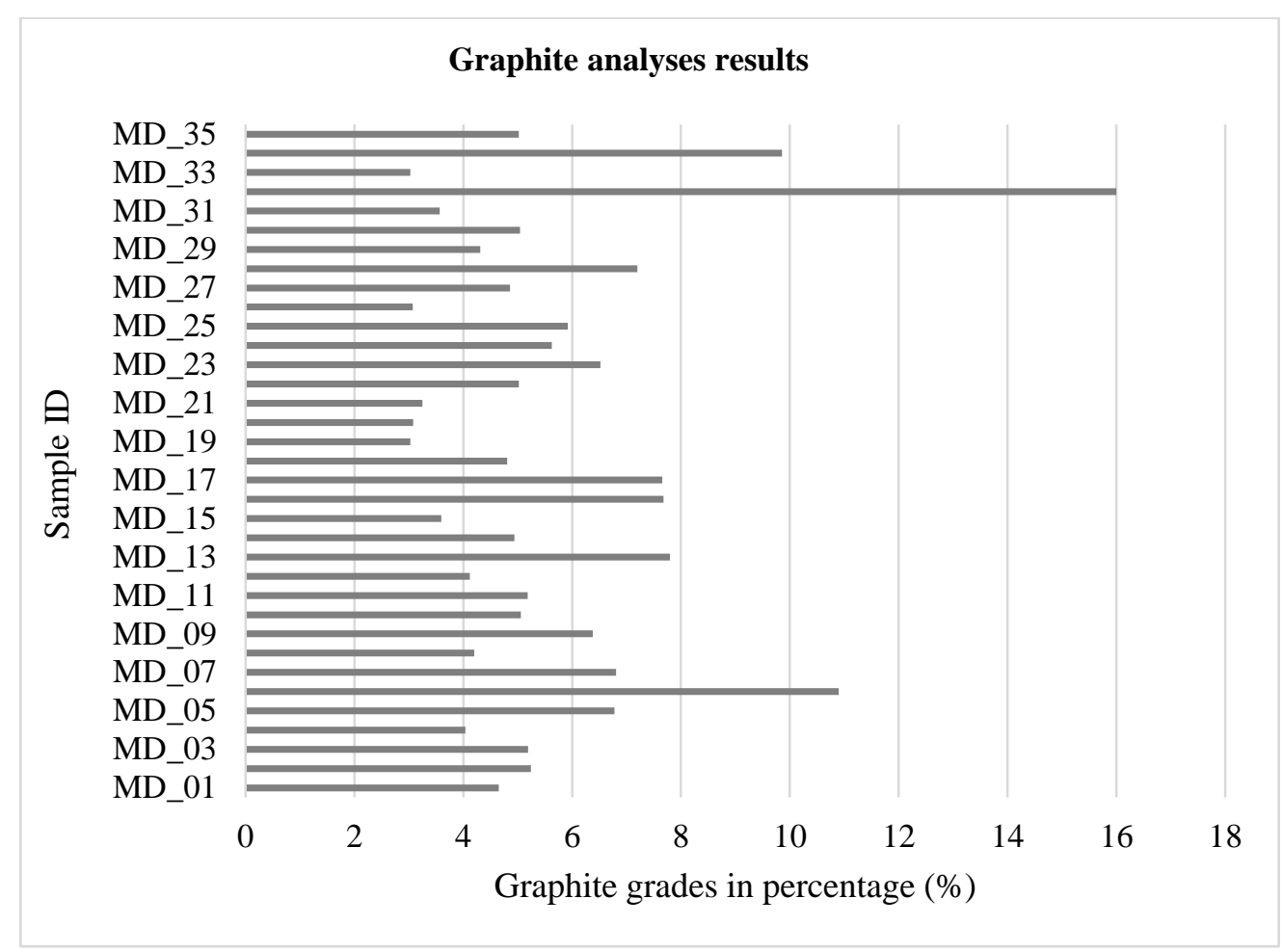

Figure 10: Graphs showing graphite analysis results by LOI.

\section{QA/QC Samples}

Duplicates, blanks and standard samples results were plotted to ascertain the reproducibility, sensitivity of the instruments used and the accuracy, respectively. The detection limit of the instrumentation and the method used was $0.5 \%$ TGC grade. The plot of the duplicate samples against their respective rock samples tends to almost overlap as shown in (Figure 11b). Hence, the duplicate results are showing the reproducibility of the method used. Also, the blank samples results are below the detection limit line (Figure 11a), indicating the agreeable sensitivity of the instrument used. Similarly, the line of the measured standard values is between the caution high and caution low lines showing the accepted deviation from the given standard value (Figure 12), and thus ascertains the accuracy of graphite analysis results. 
Moye and Msabi - Mineralogical and geochemical characteristics of graphite-bearing rocks ...
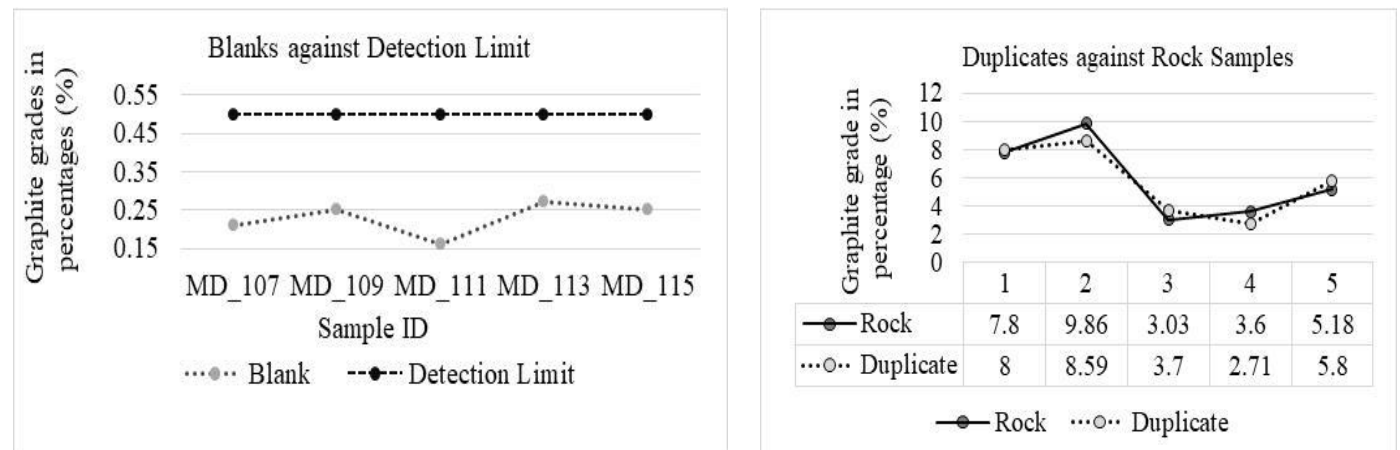

Figure 11: Graphs showing results for: (a) blank samples against detection limit of the method used to analyse graphite sample and (b) duplicate samples against the rock samples.
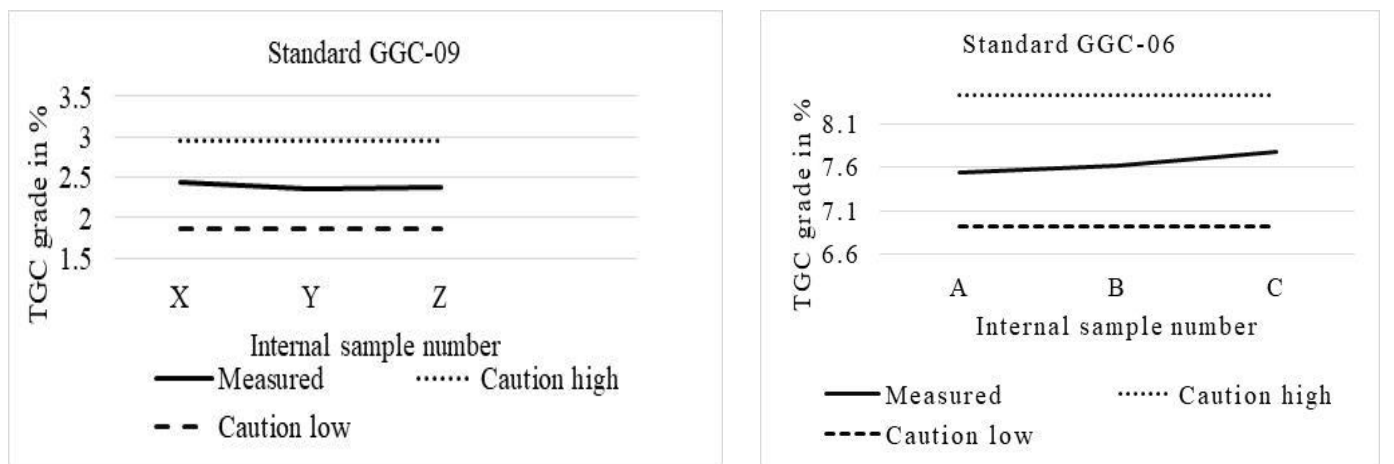

Figure 12: Graphs showing the measured values of graphite standards with respect to caution high and caution low: a) low-grade standard value (GGC-09) and b) high-grade standard value (GGC06).

\section{Discussion}

In nature, graphite occurs in two forms, namely crystalline flake graphite and cryptocrystalline graphite or commercially known as amorphous graphite (Charbonneau 2015). Amorphous graphite is formed by the low-grade thermal metamorphism of coal and it has poor crystallinity (Al-Ani and Sarapää 2016). Crystalline flake graphite can be formed in two folds. First, by regional metamorphism of preserved organic matter, which results into formation of syngenetic graphite (flake type). Second, by precipitation of $\mathrm{CH}_{4}$ or $\mathrm{CO}_{2}$ fluids which results into epigenetic graphite (veintype or lump graphite) (Mitchell 1993, Bullock and Morgan 2015, Rosing-Schow et al. 2017). Both syngenetic and epigenetic graphite are formed in medium to high-grade metamorphic facies (Al-Ani and Sarapää 2016). The medium grade of graphitic carbon content for flake graphite is $9 \mathrm{wt} . \%$, very low compared to veintype graphite which is approximately 99 wt.\% (Mitchell 1993, Charbonneau 2015, Taner et al. 2017). The flake sizes of the vein-type graphite are in the scale of centimetres to decametres, while for the flake type graphite are in the order of millimetres. Moreover, the graphite in the vein-type have flakes that fill in the fractures and pore spaces of the host lithology, while the graphite in the flake type have flakes in the matrix co-existing with the silicate minerals of the host lithology.

Field observations and petrographic examination of nature of graphite at Chenjere area support the metamorphic (syngenetic) model for its occurrences. First, graphite is in 
the matrix of the host rock and does not occur within fractures or associated with veins (Figure 4 to 8). Second, the maximum graphitic carbon content of the ore rock (graphitic gneisses) is $16 \mathrm{wt} \%$. This is in agreement with the flake type graphite and disagree with the vein-type graphite which is monomineralic with a grade of graphite approximately 99 wt.\% (Figures 2 and 10; Taner et al. 2017). Third, individual graphite flake sizes are in the order of millimetres' scale, which is consistent with other syngenetic graphite deposits (Figures 4 to 8). Fourth, graphite flakes are intergrown with silicate minerals such as feldspars, quartz and biotite (Figures 4 to 8), which support a metasedimentary origin for the graphite. Thus, field observations, petrographic investigation and geochemical analysis results are consistent with a metasedimentary model of graphite mineralization and are inconsistent with the epigenetic model or graphite formation.

The economic potential of any graphitebearing lithology is determined by graphitic carbon content and flake size since the market price for graphite considers these two characteristics (Al-Ani and Sarapää 2016). Moreover, the current workable grade of graphite is about 3 wt.\% (Pohl 2011) and the graphite grades at Chenjere area vary from 3.03 wt.\% to 16 wt.\%. Consequently, these grades are consistent with the current economical graphite deposits elsewhere around the globe. Field observations indicated that the graphite mineralization zones range in the scale of hundreds of metres to four kilometers in some places. The mineralization shows undulation along the strike lengths with the thicknesses in the order of a metre to tens of metres. These graphite mineralization extensions are consistent with graphite deposits of the economic potential elsewhere in the world (Charbonneau 2015).

\section{Conclusion}

Field observations coupled with petrographic analysis indicate that the graphite mineralization at Chenjere area is crystalline flake type with a flake size ranging from medium to coarse. This represents syngenetic rather than epigenetic type of mineralization with no evidence for the existence of amorphous graphite. As a result, this graphite mineralization in the study area points to metasedimentary origin with maximum grade of $16 \mathrm{wt} . \%$, that occurs as disseminated flakes in the graphitic gneiss host rocks. The host lithology to graphite mineralization is concordant with the rest of lithologies at the area and they both have a general trend of NESW with few exceptions. Mineralized zones occur within biotite gneiss and its extension, grade and flakes size qualifies the study area for the economic viability of graphite mineralization. However, further studies on the absolute determination of the origin and crystallinity of graphite by isotopic analysis and X-ray diffraction are recommended.

\section{Acknowledgement}

We acknowledge the financial support and analytical facilities provided by the Geological Survey of Tanzania. The University of Dodoma is acknowledged for granting research permits and Tanzoz Graphite Limited for providing access to its prospecting licenses.

\section{References}

Al-Ani T and Sarapää O 2016 Mineralogy and geochemistry of flake graphite occurrences in Joutsijärvi, Northern Finland. GTK Research Report 55, Geological Survey of Finland, 38 p.

Barker AJ 2014 A key for identification of rock-forming minerals in thin section. CRC Press.

Bullock LA and Morgan OJ 2015 A new occurrence of (gold-bearing) graphite in the Assosa region, Benishangul-Gumuz State, W Ethiopia. J. Earth Sci. Eng. 5: 417-435.

Charbonneau R 2015 Technical Report on the Buckingham Graphite Property, Southwestern Quebec, Canada.

Dissanayake CB and Chandrajith R 1999 Sri Lanka-Madagascar Gondwana linkage: Evidence for a Pan-African mineral belt. $J$. 
Geol. 107(2): 223-235.

Feneyrol J, Giuliani G, Ohnenstetter D, Fallick AE, Martelat JE, Monié P, Dubessy J, Rollion-bard C, Goff EL, Malisa E, Rakotondrazafy AFM, Pardieu V, Kahn T, Ichang D, Venance E, Voarintsoa NR, Ranatsenho MM, Simonet C, Omito E and Saul M 2013 New aspects and perspectives on tsavorite deposits. Ore Geol. Rev. 53: 125.

Fozzard P 1956 Geological map of Quarter degree sheet (QDS) 293.

Fritz H, Abdelsalam M, Ali KA, Bingen B, Collins AS, Fowler AR, Ghebreab W, Hauzenberger CA, Johnson PR, Kusky TM, Macey P, Muhongo S, Stern RJ and Viola G 2013 Orogen styles in the East African Orogen: A review of the Neoproterozoic to Cambrian tectonic evolution. Afr. Earth Sci. 86: 65-106.

Gautneb HÅV and Tveten E 2000 The geology, exploration and characterisation of graphite deposits in the Jennestad area, Vesterålen, northern Norway. Norges Geologiske Undersøkelse Bull. 436: 67-74.

Heiri O, Lotter AF and Lemcke G 2001 Loss on ignition as a method for estimating organic and carbonate content in sediments: reproducibility and comparability of results. J. Paleolimnol. 25(1): 101-110.

Jacobs J, Bingen B, Thomas R, Bauer W, Wingate MTD and Feitio P 2008 Early Palaeozoic orogenic collapse and voluminous late-tectonic magmatism in Dronning Maud Land and Mozambique: Insights into the partially delaminated orogenic root of the East African Antarctic Orogen? The Geological Society of London 308: 69-90.

Kröner A, Muhongo S, Hegner E and Wingate MT D 2003 Single-zircon geochronology and $\mathrm{Nd}$ isotopic systematics of Proterozoic high-grade rocks from the Mozambique belt of southern Tanzania (Masasi area): Implications for Gondwana assembly. $J$. Geological Society, London 160(1951): 745-757.

Kröner A and Stern R J 2005 Pan-African
Orogeny. In: Encyclopedia of Geology vol. 1, (pp 1-12), Elsevier, Amsterdam.

Leger C, Barth A, Falk D, Mruma A, Magigita M, Boniface N and Stanek K 2015 Explanatory notes for the minerogenic map of Tanzania. In Geological Survey of Tanzania. First Edition: pg 376.

Meunier E 2015 Exploring for graphite using a new ground-based time-domain electromagnetic system. Carleton University, Ottawa, Ontario, Canada.

Mitchell C 1993 Industrial Minerals Laboratory Manual: Flake graphite. In British Geological Survey. Mineralogy and Petrology Series.

Palosaari J, Latonen RM, Smått JH, Raunio S and Eklund O 2020 The flake graphite prospect of Piippumäki-an example of a high-quality graphite occurrence in a retrograde metamorphic terrain in Finland. Miner. Deposita 55: 1647-1660.

Pohl WL 2011 Economic geology: principles and practice. Wiley Blackwell Publishing. First edition: pg 680.

Puronaho L 2018 Structural interpretation of graphite- bearing black schist in Aitolampi, Eastern Finland. Master thesis, Faculty of Science and Engineering, Abo Akademi University.

Robinson G, Hammarstrom $\mathbf{J}$ and Olson D 2017 Graphite Chapter J of Critical Mineral Resources of the United States-Economic and Environmental Geology and Prospects for Future Supply Professional Paper 1802JU.S. Department of the Interior. In Professional Paper. 1802: pp. J1-J24.

Rosing-Schow N, Bagas L, Kolb J, Balić-Žunić T, Korte C and Fiorentini ML 2017 Hydrothermal flake graphite mineralisation in Paleoproterozoic rocks of south-east Greenland. Miner. Deposita. 52(5): 769789.

Sandmann D, Haser S and Gutzmer J 2014 Characterisation of graphite by automated mineral liberation analysis. Trans. Inst. Min. Metall., Sect. C 123(3): 184-189.

Simandl G, Paradis S and Akam C 2015 Graphite deposit types, their origin, and 
economic significance. British Columbia Geological Survey Paper. 3 (Symposium on Strategic and Critical Materials Proceedings): 163-171.

Stern RJ 1994 Arc assembly and continental collision in the Neoproterozoic East African Orogen: Implications for the consolidation of Gondwanaland. Ann. Rev. Earth and Planetary Sci. 22: 319-351.

Sunkari ED and Zango MS 2018 Preliminary investigation of the geologic controls of graphite mineralization and exploration potential of the Wa-Lawra Belt: Implications for Kambale graphite deposit. J. Environ. Earth Sci. 8(3): 77-89.
Taner MF, Drever C, Yakymchuk C and Longstaffe FJ 2017 Origin of graphite in the southwestern Grenville Province. Can. Mineralogist 55(6): 1041-1055.

Thomas B, Bushi AM, Roberts NMW and Jacobs J 2014 Geochronology of granitic rocks from the Ruangwa region, southern Tanzania-Links with NE Mozambique and beyond. J. Afr. Earth Sci. 100: 70-80.

Whitney DL and Evans BW 2010 Abbreviations for names of rock-forming minerals. Am. Mineral. 95(1): 185-187

Wissler M 2006 Graphite and carbon powders for electrochemical applications. J. Power Sources 156(2): 142-150. 